\title{
Entrepreneurial Self-Efficacy of University Students: A Cross-Cultural Study
}

\author{
OĞUZ BAŞOL \\ Kurklareli University, Turkey \\ oguzbasol@klu.edu.tr \\ IŞIL KARATUNA \\ Kırklareli University, Turkey \\ isilbirik@gmail.com
}

The present study investigated the entrepreneurial self-efficacy perceptions among university students across two countries, i.e., Poland and Turkey. Data were obtained through questionnaires designed to assess the perceptions of entrepreneurial self-efficacy. In all, 365 Polish and 278 Turkish students completed the questionnaires. Results indicated that Polish and Turkish students did not differ significantly in regard to the overall measure of entrepreneurial self-efficacy. Our study contributed to the entrepreneurship literature by performing a cross-cultural comparison of the perceptions of entrepreneurial self-efficacy. Thus, it provided recommendations for fostering entrepreneurial selfefficacy among university students.

Key words: entrepreneurship, cross-culture, Turkey, Poland https://doi.org/10.26493/1854-4231.12.27-40

\section{Introduction}

Entrepreneurship, considered an important ingredient of economic and social growth across the world, has been one of the most rapidly growing areas of research in academia. Such that, the number of academic studies featuring the word 'entrepreneur' in its title in the year of 1995 was nearly 300 and it was above 3.000 in the year of 2015 (see www.sciencedirect.com).

Entrepreneurial decision and behaviour are linked to several factors, including personal factors like entrepreneurial self-efficacy in entrepreneurship theory and research. Accordingly, it is stated that individuals with high entrepreneurial self-efficacy would be more prone to evaluate their entrepreneurial opportunities (Jung et al. 2001). Individuals with high entrepreneurial self-efficacy would consider an entrepreneurial environment as an environment with full of opportunities; yet, the same entrepreneurial environment 
would be perceived as an environment with full of risks and costs by individuals with low entrepreneurial self-efficacy (Chen, Greene, and Crick 1998). Moreover, even if individuals perceive the costs, risks and uncertainties of the entrepreneurial environment as identical, the ones with high entrepreneurial self-efficacy would feel more competent to deal with these uncertainties than the ones with low entrepreneurial self-efficacy (Chen, Greene, and Crick 1998). In line with these assumptions, majority of the studies that investigated entrepreneurial self-efficacy as a predictive factor in entrepreneurial intent have reported positive associations (Boyd and Vozikis 1994; Chen, Greene, and Crick 1998; Jung et al. 2001; Urban 2006).

One of the factors that affect individuals' entrepreneurial selfefficacy level is considered as the particular cultural characteristics of the society in which they live. Drawing on Hofstede's individualism-collectivism distinction (1984), entrepreneurial self-efficacy is expected to be higher in individualistic cultures than in collectivistic societies due to the certain values like higher level of internal locus, innovativeness, autonomy and competitiveness associated with individualistic cultures (Jung et al. 2001). On the contrary, entrepreneurship activities are expected to be higher in low individualist cultures according to the dissatisfaction perspective (Baum et al. 1993). From this point of view, entrepreneurial self-efficacy can also be expected to be higher in low individualistic cultures. Moreover, some of the studies did not reveal significant association between national culture and entrepreneurial self-efficacy (Mueller and Goić 2013).

In the present study, we aimed to contribute to the entrepreneurship literature by comparing the entrepreneurial self-efficacy level of a group of university students in two different social contexts, i.e., (1) Turkey and (2) Poland. Turkey and Poland are both developing countries; yet, they represent different cultures. According to Hofstede's (2001) individualism-collectivism distinction, Turkey is a collectivist and Poland is an individualistic society. Thus, based on this distinction, we investigated whether the students in individualistic Poland and in collectivistic Turkey differ in their perceptions of entrepreneurial self-efficacy.

\section{Definition of Entrepreneurship and Entrepreneurial Self-Efficacy}

The term 'entrepreneur' was first expressed by the economist Richard Cantillon in the early 18th century to refer to the person who assumes risk and management responsibility of the business en- 
terprise (Webster 1977). Since then many authors with diverse backgrounds like sociology, economics, psychology, anthropology and management have started to use the term 'entrepreneur' in their studies. For example, Hamilton and Harper (1994) defined entrepreneur as someone who exploits an invention in an environment in which adventure and risk are inherent. Caird (1990) defined entrepreneur as an innovative business owner-manager who takes calculated risks. Besides, the term entrepreneurship is defined as the process entailing entrepreneurial actions (Bellu 1993).

Global Entrepreneurship Monitor (GEM) study (2007) revealed a strong significant association between entrepreneurial activities and economic development. Moreover, studies performed in highly industrialized countries like usA, England, Canada, Germany and Japan showed a strong relation between economic development and entrepreneurship levels (Börü 2006). Apart from being an economic resource, entrepreneurship is regarded as vitally important in creating wealth and employment and in the development of society (Sondakh and Rajah 2006; Drucker 2007; Schmiemann 2008).

The importance of entrepreneurship has led many researchers to investigate the correlates of entrepreneurial intent and activities. Many of these studies have focused on the impact of personal factors. One of the personal factors that have been linked to entrepreneurial intent was the level of self-efficacy of individuals (DeNoble, Jung, and Erlich 1999; McGee et al. 2009; Pihie and Bagheri 2013). Bandura defined self-efficacy as 'beliefs in one's capabilities to organize and execute the courses of action required to produce given attainments' $(1997,3)$. In an entrepreneurial context, entrepreneurial selfefficacy is defined as an individual's confidence in his/her ability to succeed in entrepreneurial roles and tasks (Slavec and Prodan 2012). Accordingly, research that investigated the level of entrepreneurial self-efficacy specifically focused on the belief of individuals in their ability to perform entrepreneurship-related tasks (Hmieleski and Corbett 2008) like developing new product and market opportunities, building an innovative environment, initiating investor relationship, defining core purpose, coping with unexpected challenges, and developing critical human resources (De Noble, Jung, and Erlich 1999).

\section{Entrepreneurship in Poland and Turkey: \\ Differences and Similarities}

In recent years, entrepreneurship has become an economic and social phenomenon in many countries, particularly in developing countries like Turkey and Poland. Turkey is a European Union can- 
didate developing country with a population about 79 million and an annual growth rate of $3 \%$ in GDP (Pasquali 2015). Poland is a European Union member developing country with a population about 39 million and an annual growth rate of $3.3 \%$ in GDP (Pasquali 2015).

Entrepreneurship plays an important role in generating economic growth and expanding employment in both Poland and Turkey. According to the Global Entrepreneurship Monitor data (2013), established business ownership rate, i.e., adult population who are currently owner-manager of an established business was determined as $5.67 \%$ in Turkey, and $6.47 \%$ in Poland. Similar prevalence rates of nascent entrepreneurs, i.e., persons actively involved in setting up a business they will own or co-own in the adult population had been reported in Turkey (5.52\%) and Poland (5.14\%). Entrepreneurship intention rate was one of the highest among European countries with a percentage of $28 \%$ in Turkey. This rate was recorded as $17 \%$ for Poland. In Turkey $64 \%$ and in Poland $60 \%$ of the adult population reported that they consider starting a business as a career choice. Accordingly, it can be stated that in general entrepreneurship is perceived as a good career choice both in Poland and Turkey. 30.39\% of the adult population in Turkey indicated that fear of failure would prevent them from setting up a business. This rate was higher in Poland (47.80\%) (see http://www .gemconsortium.org/data/key-indicators). According to the most recent report of GEM for Turkey (2012), it is reported that in general, conditions for entrepreneurship in Turkey improved between the years 2006-2012 (see http://www.gemconsortium.org/country -profile/116). As for the Gem country report for Poland (2014), the remarkable entrepreneurial spirit and the increase in the percentage of established businesses since 2011 is reported as a very good sign (see http://www.gemconsortium.org/country-profile/99).

According to the Global Entrepreneurship and Development Index (GEDI) which ranks 132 countries on the basis of their development and business expansion, Turkey ranked 28th and Poland ranked 34th (see https://thegedi.org/global-entrepreneurship-and -development-index/). Turkey had scored higher than Poland in the entrepreneurial indicators like opportunity perception, opportunity start up, technology absorption, human capital and product innovation. On the contrary, Poland scored higher than Turkey in the indicators like networking, internationalization and cultural support. As for the indicators like competition, risk acceptance and process innovation, Poland and Turkey scored similar scores (see https://thegedi.org/tool/). 
Apart from the economic and attitudinal indicators towards entrepreneurship, cultural characteristics of a society can also be related to the development of entrepreneurship (Hofstede et al. 2004). Hofstede $(1984,82)$ defined culture as the collective programming of the mind which distinguishes one group or category of people from another' and measured national culture in four dimensions: (1) individualism-collectivism, (2) power distance, (3) uncertainty avoidance and (4) masculinity-femininity. Accordingly, an individualistic society is defined as a society where everyone is expected to look after himself or herself and his or her immediate family only (Hofstede 1984). Individualistic cultures are associated with an emphasis on independence, achievement, freedom, high levels of competition, and pleasure (Han and Shavit 1994). Its opposite, collectivism stands for a society in which individuals can expect their relatives, clan, or other in-group to look after them in exchange for unquestioning loyalty (Hofstede 1984). Collectivism subsumes concepts of interdependence, interpersonal sensitivity, conformity, mutual sympathy and self-sacrifice (Triandis 1987). Power distance defines the extent to which the less powerful persons in a society accept inequality in power and consider it normal (Hofstede 1984). Uncertainty avoidance is defined as the degree to which the members of a society feel uncomfortable with uncertainty and ambiguity (Hofstede 1984). Finally, masculinity stands for a preference in society for achievement, heroism, assertiveness and material success, while femininity refers to a preference for relationships, modesty, caring for the weak, and quality of life (Hofstede 1984).

According to Hofstede's study, both Turkey and Poland represent large power distance and strong uncertainty avoidance. However, they differ mainly in their tendencies towards individualismcollectivism and masculinity-femininity. Accordingly, Turkey is characterized by lower levels individualism and masculinity and Poland by higher levels of individualism and masculinity (Hofstede 2001). In the present study, we aimed to evaluate the entrepreneurial selfefficacy differences between Polish and Turkish university students depending on the countries' different cultural tendencies towards individualism-collectivism. Jung et al. (2001) argues that highly collectivistic cultures might not be helpful in developing entrepreneurship since in collectivist cultures people tend to avoid the conflicts that originate from new entrepreneurial ideas and innovation (Jung et al. 2001). Besides, collectives might be more likely to resist radical changes (Morris, Davis, and Allen 1994). Some of the studies that examined the association between Hofstede's cultural dimensions and 
entrepreneurship supported this view and found that high individualism is positively associated to national rates of innovation and entrepreneurship (Shane 1993; Hayton, Gerard, and Shaker 2012). Accordingly, entrepreneurial self-efficacy level should also be expected to be positively related to individualism (Jung et al. 2001). In line with this argumentation, one can claim that entrepreneurial self-efficacy of the students in individualistic Poland would be higher than the students in collectivistic Turkey.

On the contrary, there is also a valid argument that entrepreneurial activities will be observed more frequently in low individualistic cultures (Baum et al. 1993). Accordingly, it is expected that people from more individualistic societies will be more likely to satisfy their motivational needs in a common organizational environment since they are more used to dealing with people who pursue personal goals and are accustomed to getting their own way Hofstede et al., 2004). Thus, in a less individualistic society, organizations might be unsuccessful in providing people the opportunity to satisfy their personal career needs. This may lead people to start their own business since they can't satisfy their entrepreneurial needs with existing employment (Hofstede et al. 2004). This approach is labelled as the 'dissatisfaction perspective' (Baum et al. 1993; Hofstede et al. 2004). From this perspective, it can be assumed that entrepreneurial self-efficacy of the students in individualistic Poland would be lower than the students in collectivistic Turkey. Hence, there are studies supporting this assumption (Shneor, Camgöz, and Karapinar 2013). At this stage, we chose to follow the 'dissatisfaction perspective' in line with the findings of Shneor, Camgöz, and Karapinar's study (2013) which revealed that the students in collectivistic Turkey had higher selfefficacy scores than the students in individualistic Norway. Accordingly, we hypothesized that the students in an individualistic culture, in this case Poland, would report lower entrepreneurial self-efficacy than the students in a collectivist culture, in this case Turkey. The hypothesis of this study was that Polish university students would report lower levels of entrepreneurial self-efficacy than Turkish university students.

\section{Methods}

PROCEDURE AND SAMPLE

Data were collected by means of anonymous self-report questionnaires from undergraduate students in economics and administrative sciences at the University of Kırklareli (Kırklareli, Turkey) and 
Jagiellonian University (Krakow, Poland). Overall, we received 365 completed questionnaires in Poland and 278 in Turkey by using convenience sampling.

Potential participants (undergraduate students in economics and administrative sciences) at Jagiellonian University were invited to participate in the study through classroom contact within business and entrepreneurship courses in May 2016 while one of the authors (ов) was visiting Poland as a coordinator within the Erasmus mobility program. In Turkey, data were collected in March 2016 from undergraduate students in economics and administrative sciences at Kırklareli University. Participation was voluntary and participants completed the questionnaires in classroom settings both in Poland and Turkey. All questionnaires were completed anonymously to ensure confidentiality.

\section{INSTRUMENTS}

Entrepreneurial self-efficacy was measured using the entrepreneurial self-efficacy scale developed by De Noble, Jung, and Erlich (1999). The scale consists of six subscales namely: (1) developing new product and market opportunities, (2) building an innovative environment, (3) initiating investor relationships, (4) defining core purpose, (5) coping with unexpected challenges, and (6) developing critical human resources. Responses were indicated on a five-point Likert scale ( 1 = 'strongly disagree;' 5 = 'strongly agree').

In Turkey, previously validated and well-established translation of the entrepreneurial self-efficacy instrument was used (Naktiyok, Karabey, and Güllüce 2009). For the Polish version of the scale, all survey items were translated into Polish and then back-translated into English by translators fluent in both Polish and English; as, to our knowledge, there was no validated translation of the entrepreneurial self-efficacy scale in Poland.

To test the factor structure of the entrepreneurial self-efficacy measure, we used confirmatory factor analysis (CFA) using LISREL 8 and compared the measurement scale in two countries with regard to the model fit statistics. The analysis did not confirm the validity of a six factor ESE model and suggested a two-factor model fit the data best. The acceptable model fit was defined by the following goodness of fit criteria: $\chi^{2}$ significant $(p<.05), \chi^{2} / d f(\leq 5.0), \mathrm{RM}-$ SEA $(\leq 0.08), \operatorname{SRMR}(\leq 0.08), \operatorname{NFI}(\geq 0.90)$, NNFI $(\geq 0.95)$, CFI $(\geq 0.95)$, GFI ( $\geq 0.90)$, AGFI ( $\geq 0.85$ ) (Şimşek 2007; Hair et al. 2010; Kline 2011; Çelik and Yllmaz, 2013). CFA results indicated a good fit of the model to the data in Turkey $\left(\chi^{2} / d f=3.42, \mathrm{RMSEA}=0.07, \mathrm{SRMR}=0.05, \mathrm{NFI}=\right.$ 
TABLE 1 Fit Statistics for Confirmatory Factor Analysis

\begin{tabular}{lllll}
\hline$(1)$ & $(2)$ & $(3)$ & $(4)$ & $(5)$ \\
\hline$\chi^{2} / d f$ & $0 \leq \chi^{2} / d f \leq 2$ & $2 \leq \chi^{2} / d f \leq 5$ & $56.59 / 26=2.17$ & $89.07 / 26=3.42$ \\
\hline RMSEA & $0 \leq$ RMSEA $\leq 0.05$ & $0.05 \leq$ RMSEA $\leq$ & 0.06 & 0.07 \\
& & 0.08 & & \\
SRMR & $0 \leq$ SRMR $\leq 0.05$ & $0.05 \leq$ SRMR $\leq 0.08$ & 0.04 & 0.05 \\
NFI & $0.95 \leq$ NFI $\leq 1$ & $0.90 \leq$ NFI $\leq 0.95$ & 0.97 & 0.95 \\
NNFI & $0.97 \leq$ NNFI $\leq 1$ & $0.95 \leq$ NNFI $\leq 0.97$ & 0.97 & 0.95 \\
CFI & $0.97 \leq$ CFI $\leq 1$ & $0.95 \leq$ CFI $\leq 0.97$ & 0.98 & 0.96 \\
GFI & $0.95 \leq$ GFI $\leq 1$ & $0.90 \leq$ GFI $\leq 0.95$ & 0.97 & 0.93 \\
AGFI & $0.90 \leq$ AGFI $\leq 1$ & $0.85 \leq$ AGFI $\leq 0.90$ & 0.94 & 0.88 \\
\hline
\end{tabular}

Notes Column headings are as follows: (1) goodness of fit statistics, (2) good fit, (3) acceptable fit, (4) Polish sample, (5) Turkish sample. $\chi^{2}=$ chi square; $\chi^{2} / d f=$ chi square to degree of freedom ratio; RMSEA = root mean square of approximation, $\mathrm{SRMR}=$ standardized root mean square residual, $\mathrm{NFI}=$ normed fit index; $\mathrm{NNFI}=$ nonnormed fit index, CFI = comparative fit index, GFI = goodness of fit index, AGFI = adjusted goodness of fit index.

0.95, NNFI $=0.95$, CFI $=0.96$, GFI $=0.93$, AGFI $=0.88)$. The model fit was also satisfactory in Poland $\left(\chi^{2} / d f=2.17\right.$, RMSEA $=0.06$, SRMR $=$ 0.04, NFI $=0.97, \mathrm{NNFI}=0.97, \mathrm{CFI}=0.98, \mathrm{GFI}=0.97, \mathrm{AGFI}=0.94)(\mathrm{ta}-$ ble 1). The overall Cronbach's alpha for the nine-item, two-factor scale was 0.82 for the Polish sample and 0.85 for the Turkish sample. The resulting scale comprised items from two of the subscales of the original EsE (De Noble, Jung, and Erlich 1999), namely (1) developing new product and market opportunities and (2) defining core purpose. The scale included items like 'I can create products that fulfil customers' unmet needs,' 'I can discover new ways to improve existing products,' 'I can originate new ideas and products,' 'I can convince other to join with me in pursuit of my vision' and 'I can manage the negotiation process to obtain outcomes favourable to me.'

\section{Results}

Statistical analyses were carried out using sPss, version 20. As our study variables were not normally distributed (Kolmogorov-Smirnov $=p<.001$ ), we computed Mann Whitney U tests to test differences in entrepreneurial self-efficacy between the two groups. Mann Whitney U-test results for entrepreneurial self-efficacy between Polish and Turkish students are shown in table 2.

No significant relationship was found between Polish and Turkish students' perceptions of general entrepreneurial self-efficacy ( $Z=$ $-0.010 ; p=0.992)$. No significant association was detected between the two groups on the subscales 'developing new product and market 
TABLE 2 Mann Whitney U-Test Results for General Entrepreneurial Self-Efficacy and its Subscales between Polish and Turkish University Students

\begin{tabular}{lrrrrrr}
\hline Item & $(1)$ & $(2)$ & $(3)$ & $(4)$ & $(5)$ & $(6)$ \\
\hline General entrepreneurial self-efficacy & $\mathrm{P}$ & 3.71 & 0.55 & 3.67 & -0.010 & 0.99 \\
& $\mathrm{~T}$ & 3.67 & 0.64 & 3.78 & & \\
\hline Developing new product and market & $\mathrm{P}$ & 3.63 & 0.63 & 3.67 & -0.407 & 0.68 \\
opportunities & $\mathrm{T}$ & 3.62 & 0.69 & 3.67 & & \\
\hline Defining core purpose & $\mathrm{P}$ & 3.85 & 0.69 & 4.00 & -1.282 & 0.20 \\
& $\mathrm{~T}$ & 3.75 & 0.80 & 4.00 & & \\
\hline
\end{tabular}

Notes Column headings are as follows: (1) sample (P - Polish, T - Turkish), (2) mean, (3) standard deviation, (4) median, (5) test value (Z), (6) $p$.

opportunities' $(Z=-0.407 ; p=0.68)$ and 'defining core purpose' $(Z=$ $-1.282 ; p=0.20$ ). Both Polish and Turkish students scored highest in the 'defining core purpose' sub-scale.

\section{Discussion}

The present study aimed to investigate the comparison of entrepreneurial self-efficacy perceptions of a group of university students in Poland and Turkey, two countries with similar entrepreneurial indicators but different profiles on the cultural dimension of individualism/collectivism (Hofstede 2001). The findings revealed no significant differences for the level of entrepreneurial self-efficacy between the two groups (i.e., individualistic Poland vs. collectivistic Turkey), rejecting out hypothesis that Polish students would report lower entrepreneurial self-efficacy levels compared to Turkish students. In line with our hypothesis, some authors approached the issue from the dissatisfaction perspective and argued that entrepreneurial activities will be observed more frequently in low individualistic cultures (Baum et al. 1993; Hofstede et al. 2004). For example, Shneor, Camgöz, and Karapinar (2013) expected self-efficacy to be higher in collectivistic societies compared to individualistic societies. In their study among students in Norway and Turkey, they confirmed this hypothesis and found that students in collectivistic Turkey had higher self-efficacy scores than the students in individualistic Norway (Shneor, Camgöz, and Karapinar 2013). This view was not confirmed in the present study.

According to the view expressed by Jung et al. (2001), environment in highly collectivist societies compared to individualistic cultures, might not be considered as favourable for entrepreneurial activities; thus, they expected entrepreneurial self-efficacy to be higher in individualistic societies. Jung et al. (2001) found support for this 
hypothesis in their study among business students in USA and Korea, and revealed that entrepreneurial self-efficacy was significantly higher for the students in individualistic USA than the students in collectivist Korea. This view was not confirmed in the present investigation.

In addition, Mueller and Goić (2013) found no significant differences in entrepreneurial self-efficacy between undergraduate business students in highly individualistic United States and collectivist Croatia, except for the entrepreneurial tasks associated with the marshalling phase of venture creation process. Our findings were in line with Mueller and Goic's study, indicating no significant differences in entrepreneurial self-efficacy level between the university students in individualistic Poland and collectivistic Turkey.

The subscale with the highest score among Turkish students was 'defining core purpose.' A similar finding was assessed in Naktiyok, Karabey, and Güllüce's (2009) study in which they investigated the entrepreneurial self-efficacy and intention of 245 undergraduate students of a university in Turkey. Accordingly, it can be stated that Turkish students believe themselves to be successful in articulating vision and values of the organization and inspiring others to embrace vision and values of the organization. As for the Polish sample, the subscale with the highest score was also 'defining core purpose.' Thus, as in the Turkish sample, Polish students also do feel confident in articulating vision and values of the organization and inspiring others to embrace vision and values of the organization. In addition, they perceive themselves to be competent in creating a working environment that encourages people to try out something new and fostering an interactive working environment.

In conclusion, our study findings revealed no significant difference between Polish and Turkish students' perceptions of general entrepreneurial self-efficacy. Yet, there are a number of reasons to be cautious in interpreting the results. First of all, this study was based on cross-sectional data, from which it is difficult to make causal inferences; thus, associations between study variables should be considered carefully before drawing some conclusions. Second, participants were recruited through convenience sampling, which weakens research objectivity and limits the generalizability of the findings. Third, majority of the questionnaires conducted in Poland contained incomplete responses to demographic questions; thus, demographic variables were discarded from the analysis. Future studies should also investigate the entrepreneurial self-efficacy perceptions due to gender, age or level of education etc. Fourth, this study 
aimed to evaluate the entrepreneurial self-efficacy of students in two countries which are distinguished particularly by their cultural characteristics in terms of individualism/collectivism and masculinity/femininity. And, in this study we particularly focused on the individualism/collectivism dimension of culture. Therefore, further cross studies should investigate entrepreneurial self-efficacy in nations that have the opposite cultural characteristics in each dimension of culture. Finally, the ESE scale used in this study did not present data on the entrepreneurial self-efficacy sub-categories like 'coping with unexpected challenges,' 'building an innovative environment,' 'initiating investor relationships' and 'developing critical human resources,' as the confirmatory factor analysis did not confirm the validity of a six factor ESE model (De Noble, Jung, and Erlich 1999). Therefore, findings of this study suggest the need for further research in this area.

Despite the limitations mentioned, our study contributed to the entrepreneurship literature by performing a cross-cultural comparison of the perceptions of entrepreneurial self-efficacy. Entrepreneurial self-efficacy has been considered as a potential predictor of entrepreneurial activities (Jung et al. 2001). Thus, improving the entrepreneurial self-efficacy of university students i.e., future entrepreneurs, would help improve entrepreneurial drive. Thus, a practical implication of this work is that students should be encouraged to attend the entrepreneurship courses in universities to improve their competencies and to obtain entrepreneurial skills. Furthermore, establishing facilities like coffee shops and cafeterias in university settings and creating management opportunities for students would help them build experience and improve their entrepreneurial self-efficacy (see https://leadership.uchicago.edu/ student-run-coffee-shops; http://ssmu.mcgill.ca/about-us/ operations/studentruncaf/).

\section{References}

Bandura, A. 1997. Self-Efficacy: The Exercise of Control. New York: Freeman.

Baum, J. R., J. D. Olian, M. Erez, E. R. Schnell, K. G. Smith, H. P. Sims, J. S. Scully, and K. A. Smith. 1993. 'Nationality and Work Role Interactions: A Cultural Contrast of Israeli and us Entrepreneurs' versus Managers' Needs.' Journal of Business Venturing 8:499-512.

Bellu, R. R. 1993. 'Task Role Motivation and Attributional Style as Predictors of Entrepreneurial Performance: Female Sample Findings.' Entrepreneurship and Regional Development 5:331-44. 
Börü, D. 2006. Girişimcilik Eğilimi: M. Ü. İşletme Bölümü Öğrencileri Üzerinde bir Araştırma. Istanbul: Marmara Üniversitesi.

Boyd, N. G., and G. S. Vozikis. 1994. 'The Influence of Self-Efficacy on the Development of Entrepreneurial Intentions and Actions.' Entrepreneurship Theory and Practice 18:63-90.

Caird, S. 1990. 'What Does It Mean to Be Entrerprising.' British Journal of Management 1:137-45.

Çelik, H. E., and V. Yılmaz. 2013. Lisrel 9.1 ile Yapısal Eşitlik Modellemesi. Ankara: Anı Yayıncılık.

Chen, C. C., P. G. Greene, and A. Crick. 1998. 'Does Entrepreneurial Self-Efficacy Distinguish Entrepreneurs from Managers?' Journal of Business Venturing 13:295-316.

DeNoble, A. F., D. Jung, and S. B. Ehrlich. 1999. ‘Entrepreneurial SelfEfficacy: The Development of a Measure and Its Relationship to Entrepreneurial Action.' http://www.babson.edu/entrep/fer/papers99/ I/I_C/IC.html

Drucker, P. F. 2007. Innovation and Entrepreneurship. Oxford: Butterworth-Heinemann.

Global Entrepreneurship Monitor. 2007. Global Report on High-Growth Entrepreneurship. Babson Park, MA: Babson College; London: London Business School.

- 2013. Fifteen Years of Assessing Entrepreneurship Across the Globe. Bobson Park, mA: Babson College.

Hair, J. F., W. C. Black, B. J. Babin, and R. E. Anderson. 2010. Multivariate Data Analysis: A Global Perspective. 7th ed. Upper Saddle River, NJ: Pearson Education.

Hamilton, R. T., and D. A. Harper. 1994. 'The Entrepreneur in Theory and Practice.' Journal of Economic Studies 21 (6): 3-18.

Han, S., and S. Shavitt. 1994. 'Persuasion and Culture: Advertising Appeals in Individualistic and Collectivistic Countries.' Journal of Experimental Social Psychology 30:326-50.

Hayton, J. C., G. Gerard, and A. Z. Shake. 2002. 'National Culture and Entrepreneurship: A Review of Behavioral Research.' Entrepreneurship: Theory and Practice 26 (4): 33-52.

Hmieleski, K. M., and A. C. Corbett. 2008. 'The Contrasting Interaction Effects of Improvisational Behavior with Entrepreneurial SelfEfficacy on New Venture Performance and Entrepreneur Work Satisfaction.' Journal of Business Venturing 23 (4): 482-96.

Hofstede, G. 1984. 'Cultural Dimensions in Management and Planning.' Asia Pacific Journal of Management 1 (2): 81-99.

Hofstede, G. 2001. Culture's Consequences: Comparing Values, Behaviors, Institutions, and Organizations Across Nations. 2nd ed. Thousand Oaks, cA: Sage.

Hofstede, G., N. Noorderhaven, A. R. Thurik, L. M. Uhlaner, A. R. M. Wennekers, and R. E. Wildeman. 2004. 'Culture's Role in Entre- 
preneurship: Self-Employment out of Dissatisfaction.' In Innovation, Entrepreneurship and Culture, edited by T. E. Brown and J. M. Ulijn, 162-203. Cheltenham: Edward Elgar.

Jung, D. I., S. B. Ehrlich, A. F. DeNoble, and K. B. Baik. 2001. 'Entrepreneurial Self-Efficacy and its Relationship to Entrepreneurial Action: A Comparative Study Between the us and the Korea.' Management International 6 (1): 41-54.

Kline, R. B. 2011. Principles and Practice of Structural Equation Modeling. New York: Guilford.

McGee, J. E., M. Peterson, S. L. Mueller, and J. M. Sequeira. 2009. 'Entrepreneurial Self-Efficacy: Refining the Measure.' Entrepreneurship Theory and Practice 33 (4): 965-88.

Morris, M. H., D. L. Davis, and J. W. Allen. 1994. 'Fostering Corporate Entrepreneurship: Cross-Cultural Comparisons of the Importance of Individualism versus Collectivism.' Journal of International Business Studies 25 (1): 65-89.

Mueller, S. L., and S. Goić. 2003. 'East-West Differences in Entrepreneurial Self-Efficacy: Implications for Entrepreneurship Education in Transition Economies.' International Journal of Entrepreneurship Education 1 (4): 613-32.

Naktiyok, A., C. N. Karabey, and A. Ç. Güllüce. 2009. 'Entrepreneurial Self-Efficacy and Entrepreneurial Intention: The Turkish Case.' International Entrepreneurship and Management Journal 6 (4): 419-35.

Pasquali, V. 2015. 'Countries with Highest GDP Growth.' Global Finance, 1 November. https://www.gfmag.com/global-data/economic-data/ countries-highest-gdp-growth

Pihie, Z. A. L., and A. Bagheri. 2013. 'Self-Efficacy and Entrepreneurial Intention: The Mediation Effect of Self-Regulation.' Vocations and Learning 6:385-401.

Schmiemann, M. 2008. 'Enterprises by Size Class - Overview of SMEs in the EU.' Statistics in Focus 31, Eurostat, Luxembourg.

Shane, S. 1993. 'Cultural Influences on National Rates of Innovation.' Journal of Business Venturing 8:59-73

Shneor, R., S. M. Camgöz, and P. B. Karapinar. 2013. 'The Interaction between Culture and Sex in the Formation of Entrepreneurial Intentions.' Entrepreneurship \& Regional Development 25 (9-10): 781-803.

Şimşek, Ö. F. 2007. Yapısal Eşitlik Modellemesine Giriş. Ankara: Ekinoks.

Slavec, A., and I. Prodan. 2012. 'The Influence of Entrepreneur's Characteristics on Small Manufacturing Firm Debt Financing.' Journal of East European Management Studies 17 (1): 104-30.

Sondakh, D. F., and K. K. Rajah. 2006. 'Developing an Entrepreneurship Culture, The Greenwich Experience.' Entrepreneurship and Innovation 7 (4): 231-41.

Triandis, H. C. 1987. 'Collectivism vs. Individualism: A Reconceptualization of a Basic Concept in Cross-Cultural Social Psychology.' In Per- 
sonality, Cognition and Values: Cross-Cultural Perspectives of Childhood and Adolescence, edited by C. Bagley and G. K. Verma, 60-95. London: Macmillan.

Urban, B. 2006. 'Entrepreneurship in the Rainbow Nation: Effect of Cultural Values and ESE on Intentions.' Journal of Developmental Entrepreneurship 11 (3): 171-86.

Webster, F. A. 1977. 'Entrepreneurs and Ventures: An Attempt at Classification and Clarification.' Academy of Management 2 (1): 54-61.

This paper is published under the terms of the Attribution-

NonCommercial-NoDerivatives 4.o International (CC BY-NC-ND 4.0)

License (http://creativecommons.org/licenses/by-nc-nd/4.o/). 